This item was submitted to Loughborough's Research Repository by the author.

Items in Figshare are protected by copyright, with all rights reserved, unless otherwise indicated.

\title{
Prevalence and frequency of menstrual cycle symptoms are associated with availability to train and compete: a study of 6812 exercising women recruited using the Strava exercise app
}

\section{PLEASE CITE THE PUBLISHED VERSION}

https://doi.org/10.1136/bjsports-2020-102792

\section{PUBLISHER}

BMJ

\section{VERSION}

AM (Accepted Manuscript)

\section{PUBLISHER STATEMENT}

This article has been accepted for publication in British Journal of Sports Medicine, 2021 following peer review, and the Version of Record can be accessed online at https://doi.org/10.1136/bjsports-2020-102792.

\section{LICENCE}

CC BY-NC 4.0

\section{REPOSITORY RECORD}

Bruinvels, Georgie, Esther Goldsmith, Richard Blagrove, Andrew Simpkin, Nathan Lewis, Katie Morton, Ara Suppiah, et al.. 2020. "Prevalence and Frequency of Menstrual Cycle Symptoms Are Associated with Availability to Train and Compete: A Study of 6812 Exercising Women Recruited Using the Strava Exercise App". Loughborough University. https://hdl.handle.net/2134/13614257.v1. 
The prevalence and frequency of menstrual cycle symptoms are associated with women's availability to train and compete: A study of 6,812 exercising women recruited using the Strava exercise app

Bruinvels $\mathrm{G}^{1,2}$, Goldsmith $\mathrm{E}^{2}$, Blagrove $\mathrm{RC}^{3}$, Simpkin $\mathrm{AJ}^{4,5}$, Lewis $\mathrm{NA}^{1,2}$, Morton $\mathrm{K}^{2}$, Suppiah $\mathrm{A}^{2,6}$, Rogers $\mathrm{JP}^{7,8}$, Ackerman $\mathrm{KE}^{9}$, Newell $\mathrm{J}^{4,5}$, Pedlar $\mathrm{CR}^{1,2,10}$

${ }^{1}$ Faculty of Sport, Health and Applied Science, St Mary's University, Waldegrave Road, Twickenham, UK ${ }^{2}$ Orreco Ltd., Unit 103, Business Innovation Centre, NUI Galway, Galway, Ireland.

${ }^{3}$ Loughborough University, School of Sport, Exercise and Health Sciences, Epinal Way, Loughborough, UK ${ }^{4}$ School of Mathematics, Statistics and Applied Mathematics, National University of Ireland, Galway, Ireland

${ }^{5}$ Insight Centre for Data Analytics, National University of Ireland, Galway, Ireland

${ }^{6}$ University of Central Florida, Orlando, FL, USA

${ }^{7}$ Manchester Institute of High Performance, Manchester, UK

${ }^{8}$ Manchester University NHS Foundation Trust, Manchester, UK

${ }^{9}$ Female Athlete Program, Division of Sports Medicine, Boston Children's Hospital and Harvard Medical School, 300 Longwood Ave, Boston, USA

${ }^{10}$ Institute of Sport, Exercise and Health, Division of Surgery and Interventional Science, University College London, London, UK

Corresponding author email address: georgie.bruinvels@orreco.com 


\begin{abstract}
Objectives: The menstrual cycle can affect sports participation and exercise performance. There are very few data on the specific menstrual cycle symptoms (symptoms during various phases of the cycle, not only during menstruation) experienced by exercising women. We aimed to characterise the most common symptoms; the number and frequency of symptoms; and we evaluated whether menstrual cycle symptoms were associated with sporting outcomes.
\end{abstract}

Methods: 6,812 adult women of reproductive age (mean age: 38.3 (8.7) years) who were not using combined hormonal contraception were recruited via the STRAVA exercise app user database and completed a 39part survey. Respondents were from seven geographical areas, and questions were translated and localised to each region (Brazil, $n=1,288$; France, $n=1,911$; Germany, $n=1,178$; Spain, $n=1,204$; UK \& Ireland, $\mathrm{n}=2,311$; and USA, $\mathrm{n}=2,479$ ). The survey captured exercise behaviours; current menstrual status; the presence and frequency of menstrual cycle symptoms; medication use for symptoms; perceived effects of the menstrual cycle on exercise and work behaviours; and history of hormonal contraception use. We propose a novel Menstrual Symptom index (MSi) based on the presence and frequency of 18 commonly reported symptoms (range 0-54 where 54 would be all 18 symptoms each occurring very frequently).

Results: The most prevalent menstrual cycle symptoms were mood changes/anxiety (90.6\%), tiredness/fatigue (86.2\%), stomach cramps (84.2\%), and breast pain/tenderness (83.1\%). After controlling for BMI, training volume and age, the Menstrual Symptom Index was associated with a greater likelihood of missing or changing training $(\mathrm{OR}=1.09(\mathrm{CI}: 1.08,1.10) ; \mathrm{p}<0.05)$, missing a sporting event/competition $(\mathrm{OR}=1.07$ (CI: 1.06,1.08); $\mathrm{p}=<0.05)$, absenteeism from work/academia (OR=1.08 (CI: 1.07,1.09); $\mathrm{p}=<0.05)$, and use of pain medication $(\mathrm{OR}=1.09(\mathrm{CI}: 1.08,1.09) ; \mathrm{p}=<0.05)$.

Conclusion: Menstrual cycle symptoms are very common in exercising women and women report that these symptoms compromise their exercise participation and work capacity. The Menstrual Symptom Index needs to be formally validated (psychometrics); at present it provides an easy way to quantify the frequency of menstrual cycle symptoms.

Keywords

Period; menstruation; sport; inflammation; survey

What are the new findings:

- Menstrual cycle symptoms are reported to have a detrimental effect on exercise and work capacity

- The most common symptoms experienced were mood changes/anxiety, tiredness/fatigue and stomach cramps.

- A scoring system (Menstrual Symptom index; MSi) was created based on the occurrence and frequency of symptoms.

- A higher menstrual symptom index was associated with an increased likelihood of negative outcomes such as missing training or competition.

How might it impact on clinical practice in the near future:

- Medical professionals should consider screening exercising women for menstrual cycle symptoms.

- Where a large number of menstrual cycle symptoms are present, or the symptoms appear to impact performance, training and work, clinicians could pay more attention to planning training and recovery accordingly. 
- The Menstrual Symptom index (MSi) may aid clinicians in their screening of sportswomen, and help clinicians evaluate interventions being used to treat symptoms.

\section{Introduction}

In the female population, menstrual pain is the most common gynaecological issue,[1] reducing quality of life, limiting work capacity, and causing absenteeism from school, work and social activities.[2-4] Physical activity provides a means for managing menstrual cycle symptoms (MCS), with aerobic exercise and yoga in particular demonstrably reducing menstrual cycle-related pain.[5] Within the athletic population, 51-93\% of athletes self-report performance detriments, or negative experiences broadly associated with their menstrual cycle.[6-8] However, the specific reasons for performance detriments have not been investigated. In the general population, up to $90 \%$ of women experience premenstrual symptoms, and $20-90 \%$ experience premenstrual syndrome (PMS).[9,10] Yet, the prevalence and impact of symptoms related to the menstrual cycle (menstrual cycle symptoms; MCS; including symptoms at any time in the cycle) has not previously been evaluated in the athletic population, and there is no existing method for quantifying MCS.

The two most common conditions characterised by pain associated with the menstrual cycle are PMS and primary dysmenorrhea (PD). Due to the lack of a universal consensus on diagnosis, the epidemiology of both conditions varies significantly. PMS involves a range of physical and/or psychological symptoms in the days prior to menstruation.[11] PD is a term used to describe chronic and cyclic pain just before and/or during menstruation, where there is no underlying pathology evident.[12] Some can also experience pain around ovulation.[13]

The aims of the present study were to: 1) describe MCS among exercising women; 2) evaluate the relationship between MCS and negative events, including the need to miss or change training/competition, use of pain medication, and missing work/lectures; and 3) quantify prevalence and occurrence of symptoms, with a novel Menstrual Symptom index (MSi).

\section{Materials and methods}

Study population and survey dissemination

The survey was disseminated via email from the STRAVA membership database (including only women who opted in to receiving emails of this nature) and through the STRAVA application via a hyperlink. The inclusion criteria were for participants to be female and aged 18-years and older (mean age: 38.3 (8.7) years). The derivation of the sample for this study is shown in Figure 1. A total of 425,697 women received an invitation to complete an online survey (180,000 via email, 245,697 via the STRAVA mobile application). Of this sample, 16,423 (3.9\%) initiated the survey, and 10,371 (2.4\%) completed the survey. From start to end, the completion rate was $63.1 \%$. The survey was open for 25 days and launched on 14 February 2019 until 11 March 2019. The participants reported partaking in a wide range of exercise types, including running, swimming, cycling, dance classes, team sports, gym-based classes, racket sports, use of a crosstrainer or similar cardio-based exercise machine, martial arts, weight training, and other forms of prolonged exercise.

\section{Research design}

An online survey was created (www.surveymonkey.com; SurveyMonkey, London) to evaluate menstrual characteristics, symptoms and exercise habits in a cross-sectional sample of exercising females. The survey was designed to take approximately 10 -minutes to complete. Following feedback from a pilot survey $(\mathrm{n}=20$; ages $18-40$ years) to help evaluate face validity and general clarity around questions, minor alterations were made to the question order and grammar. The final survey comprised 39-questions. 
The survey included questions on the following topics: current and previous exercise behaviours (including self-reported training volume and intensity); current menstrual status; the presence of, and frequency of experiencing MCS; use of pain medication for MCS (e.g., non-steroidal anti-inflammatory drugs; NSAIDs); effects of the menstrual cycle on exercise behaviours and work capacity; hormonal contraception use; the effect of exercise on MCS; communication and education around the menstrual cycle; aspects of diet and sleep; and iron status. The survey was translated into French, Spanish, Brazilian Portuguese, German and American English. It was then localised to seven countries (United Kingdom and Northern Ireland, Republic of Ireland, United States of America, France, Spain, Italy and Germany) by a native language speaker to ensure correct meaning and colloquialism, and subsequently piloted within these countries for affirmation. All questions were multiple choice, checkboxes with or without a limit on the number of selections allowed, dropdown of answer choices, a matrix or a slider. Free text answers were not requested except for instances where an 'Other' was applicable (on nine occasions). Logic was applied to the survey to ensure that only relevant questions were asked.

\section{Ethical approval}

The study protocol was approved by the Ethics Committee of St Mary's University, Twickenham, UK and participants provided informed consent prior to commencing the survey.

\section{Survey analysis}

The raw data were exported from SurveyMonkey directly into Microsoft Excel for Mac software. Those participants who were using combined hormonal birth control (containing both exogenous oestrogen and progesterone; $n=1,285 ; 12.4 \%)$, those who indicated being peri- or post-menopausal $(n=1,781 ; 17.2 \%)$, and those who indicated that they have been pre- or post-partum $(\mathrm{n}=493 ; 4.8 \%)$ in the last year were removed. Those using combined hormonal birth control were excluded from this dataset due to the known systemic metabolic and inflammatory effects that the exogenous hormones have.[20] As progestin-only birth control options do not exhibit the same systemic metabolic response, users of this type of hormonal contraception were included in this analysis.[20] As a result, the total sub-analysis population was 6,812 (Figure 1).

Menstrual Symptom index (MSi)

Participants were asked to report experience of symptoms. Specific symptoms listed were a combination of those examined in previous work.[15] To calculate the Menstrual Symptom index (MSi) a Likert scale was used based on frequency of each symptom. Where an individual reported a symptom 'often', it was given 3 points, 'sometimes': 2 points, 'rarely': 1 point, and 'never': 0 points. Points were then summed to create that athlete's Menstrual Symptom index (MSi). Because there were 18 symptoms, total scores ranged from 0 (minimum) to 54 (every symptom, often). The number of symptoms reported regardless of the frequency were also added to create 'total number of symptoms' - a value out of 18. Quantifying menstrual symptom frequency in this way was not formally validated.

Women were also asked to indicate if menstrual cycle symptoms led to them missing training/a sporting event, missing work, or the use of pain medication using the following scale; 'no, never', 'yes, rarely', yes, sometimes (every few cycle)', or 'yes, often (every cycle)'.

Statistical analysis

All analyses were performed using R (version 3.5.1). Numerical and graphical summaries were generated to describe the target population of interest and to estimate the number and frequency of symptoms experienced in the cohort of exercising women by country of origin.

A separate logistic regression model was fitted to evaluate the association between the Menstrual Symptom index and the probability of missing/changing training, missing a sporting competition/event, missing 
work/lectures and use of pain medication, while adjusting for BMI, training volume and age. The odds ratio for each variable and accompanying $95 \%$ confidence interval were calculated.

\section{Results}

The demographics of the exercising women that met the inclusion criteria are shown in Table 1. 
Table 1 - Demographics of the sample of exercising women $(n=6,812)$ by country, where categorical variables are summarised as count (percentage), and continuous variables as mean (standard deviation).

\begin{tabular}{|c|c|c|c|c|c|c|c|c|}
\hline Country & $\begin{array}{c}\mathrm{n}(\% \text { of } \\
\text { total } \\
\text { sample })\end{array}$ & $\begin{array}{l}\text { Weekly } \\
\text { exercise } \\
\text { volume } \\
\text { (minutes) }\end{array}$ & $\begin{array}{c}\text { BMI } \\
\left(\mathrm{kg} \cdot \mathrm{m}^{-2}\right)\end{array}$ & $\begin{array}{c}\text { Age } \\
\text { (years) }\end{array}$ & $\begin{array}{l}\text { Number } \\
\text { of } \\
\text { menstrual } \\
\text { cycle } \\
\text { symptoms }\end{array}$ & $\begin{array}{l}\text { Menstrual } \\
\text { Symptom } \\
\text { index } \\
\text { (MSi) }\end{array}$ & $\begin{array}{l}\text { Number of } \\
\text { 'often' } \\
\text { symptoms } \\
\text { out of } 18 \\
\text { total }\end{array}$ & $\begin{array}{c}\text { Experiences } \\
\text { at least } 1 \\
\text { symptom } \\
\text { 'often' }\end{array}$ \\
\hline Brazil & $\begin{array}{c}892 \\
(13.1 \%)\end{array}$ & $\begin{array}{c}634.1 \\
(511.1)\end{array}$ & $\begin{array}{l}23.9 \\
(3.7)\end{array}$ & $\begin{array}{l}37.5 \\
(8.1)\end{array}$ & $\begin{array}{r}12.4 \\
(3.9)\end{array}$ & $\begin{array}{c}25.8 \\
(10.2)\end{array}$ & $\begin{array}{c}3.8 \\
(2.9)\end{array}$ & $\begin{array}{c}88.0 \% \\
(785)\end{array}$ \\
\hline France & $\begin{array}{c}1355 \\
(19.9 \%)\end{array}$ & $\begin{array}{c}414.3 \\
(318.4)\end{array}$ & $\begin{array}{l}21.9 \\
(2.9)\end{array}$ & $\begin{array}{l}37.7 \\
(9.1)\end{array}$ & $\begin{array}{c}9.6 \\
(4.3)\end{array}$ & $\begin{array}{c}19.0 \\
(10.3)\end{array}$ & $\begin{array}{c}2.6 \\
(2.5)\end{array}$ & $\begin{array}{l}77.5 \% \\
(1050)\end{array}$ \\
\hline Germany & $\begin{array}{c}839 \\
(12.3 \%)\end{array}$ & $\begin{array}{c}500.5 \\
(362.1)\end{array}$ & $\begin{array}{l}22.7 \\
(3.1)\end{array}$ & $\begin{array}{l}38.6 \\
(9.0)\end{array}$ & $\begin{array}{c}9.6 \\
(4.2)\end{array}$ & $\begin{array}{c}17.9 \\
(10.1)\end{array}$ & $\begin{array}{c}2.3 \\
(2.5)\end{array}$ & $\begin{array}{c}68.4 \% \\
(574)\end{array}$ \\
\hline Spain & $\begin{array}{c}834 \\
(12.2 \%)\end{array}$ & $\begin{array}{c}633.4 \\
(476.6)\end{array}$ & $\begin{array}{l}21.9 \\
(2.9)\end{array}$ & $\begin{array}{l}39.8 \\
(8.8)\end{array}$ & $\begin{array}{l}10.9 \\
(4.0)\end{array}$ & $\begin{array}{l}22.1 \\
(9.9)\end{array}$ & $\begin{array}{c}3.2 \\
(2.7)\end{array}$ & $\begin{array}{c}83.6 \% \\
(697)\end{array}$ \\
\hline UK & $\begin{array}{c}1350 \\
(19.8 \%)\end{array}$ & $\begin{array}{c}529.9 \\
(375.1)\end{array}$ & $\begin{array}{l}23.9 \\
(4.1) \\
\end{array}$ & $\begin{array}{l}38.8 \\
(8.5) \\
\end{array}$ & $\begin{array}{l}12.5 \\
(4.2)\end{array}$ & $\begin{array}{c}26.0 \\
(11.1) \\
\end{array}$ & $\begin{array}{c}3.8 \\
(3.2)\end{array}$ & $\begin{array}{l}84.7 \% \\
(1144) \\
\end{array}$ \\
\hline USA & $\begin{array}{c}1542 \\
(22.6 \%)\end{array}$ & $\begin{array}{c}565.7 \\
(363.3)\end{array}$ & $\begin{array}{l}23.6 \\
(4.2)\end{array}$ & $\begin{array}{l}37.6 \\
(8.5)\end{array}$ & $\begin{array}{l}12.4 \\
(4.2)\end{array}$ & $\begin{array}{c}25.3 \\
(10.9)\end{array}$ & $\begin{array}{c}3.6 \\
(3.1)\end{array}$ & $\begin{array}{l}82.8 \% \\
(1277)\end{array}$ \\
\hline Total & $\begin{array}{c}6812 \\
(100 \%)\end{array}$ & $\begin{array}{c}537.7 \\
(402.1)\end{array}$ & $\begin{array}{l}23.0 \\
(3.7)\end{array}$ & $\begin{array}{l}38.3 \\
(8.7)\end{array}$ & $\begin{array}{l}11.3 \\
(4.4)\end{array}$ & $\begin{array}{c}22.9 \\
(11.0)\end{array}$ & $\begin{array}{c}3.6 \\
(3.3)\end{array}$ & $\begin{array}{l}81.1 \% \\
(5527)\end{array}$ \\
\hline
\end{tabular}

$\mathrm{SD}=$ standard deviation 
Prevalence and frequency of reporting each symptom

The prevalence and reported frequency of each symptom is shown in Figure 2. The most common symptom regardless of frequency was 'mood changes/anxiety', reported by $90.6 \%$ of the total sample. 'Mood changes/anxiety' was also the symptom most commonly reported 'often' ( $44.1 \%$ of the sample). The next most common symptoms reported 'often' were 'cravings/increased appetite' (37.6\%), 'breast pain/tenderness' (36.7\%) and tiredness/fatigue (33.1\%).

A number of symptoms were also cited in the 'Other' free text box. Those cited by more than one individual and were not duplicated from the other symptoms included heavy/achy legs $(\mathrm{n}=9)$, depression-like symptoms $(n=7)$, pelvic/uterine/ovarian pain $(n=6)$, increased sweating $(n=5)$, loss of appetite $(n=3)$, clumsiness $(n=2)$, feelings of getting cold/flu like symptoms $(n=2)$, urinary incontinence $(n=2)$, increased thirst $(n=2)$, increased heart rate $(\mathrm{n}=2)$.

Total number of symptoms and Menstrual Symptom index

The mean number of menstrual cycle symptoms experienced was 11.3 (95\% CI 11.21 to 11.41 , Figure 3a,) while the mean Menstrual Symptom index was 22.9 (95\% CI 22.66 to 23.18, Figure 3b).

Association between Menstrual Symptom index and missing training, competition or work and use of pain medication

Table 2 shows the effect of the Menstrual Symptom index on the probability of missing/changing training, missing a sporting event/competition or missing work/lectures while adjusting for a woman's BMI, age and training volume as covariates. The odds ratios for the Menstrual Symptom index provider an estimate of the change in odds for the corresponding response variable, per unit increase in Menstrual Symptom index score. A higher Menstrual Symptom index (when adjusting for age, BMI and training volume) was significantly associated with missing/changing training, missing a sporting event/competition, missing work/lectures, and pain medication use. We estimate that the odds of missing training are multiplied by 1.09 per unit increase in Menstrual Symptom index.

Table 2 - Estimated odds ratio and 95\% confidence intervals for the (adjusted) effect of Menstrual Symptom index on missing training, missing a sporting event/competition or work. Values are odds ratio $(95 \% \mathrm{CI})$. Odds ratios deemed significant $(\mathrm{p}<0.05)$ are shown in bold.

\begin{tabular}{|l|c|c|c|c|}
\hline & $\begin{array}{c}\text { Missing/changing } \\
\text { training }\end{array}$ & $\begin{array}{c}\text { Missing a sporting } \\
\text { event/competition }\end{array}$ & $\begin{array}{c}\text { Missing } \\
\text { work/lectures }\end{array}$ & $\begin{array}{c}\text { Pain medication } \\
\text { use }\end{array}$ \\
\hline Intercept & $\mathbf{0 . 4 3}$ & $\mathbf{0 . 0 6}$ & $\mathbf{0 . 0 9}$ & $\mathbf{0 . 4 5}$ \\
& $\mathbf{( 0 . 2 7 , 0 . 6 7 )}$ & $\mathbf{( 0 . 0 4 , 0 . 0 9 )}$ & $\mathbf{( 0 . 0 6 , 0 . 1 4 )}$ & $\mathbf{( 0 . 2 9 , 0 . 6 8 )}$ \\
\hline $\begin{array}{l}\text { Menstrual Symptom } \\
\text { index (count) }\end{array}$ & $\mathbf{1 . 0 9}$ & $\mathbf{1 . 0 7}$ & $\mathbf{1 . 0 8}$ & $\mathbf{1 . 0 9}$ \\
& $\mathbf{( 1 . 0 8 , 1 . 1 0 )}$ & $\mathbf{( 1 . 0 6 , 1 . 0 8 )}$ & $\mathbf{( 1 . 0 7 , 1 . 0 9 )}$ & $\mathbf{( 1 . 0 8 , 1 . 0 9 )}$ \\
\hline BMI (kg.m ${ }^{-2}$ ) & $\mathbf{1 . 0 5}$ & 1.01 & $\mathbf{1 . 0 3}$ & $\mathbf{1 . 0 2}$ \\
& $\mathbf{( 1 . 0 3 , 1 . 0 7 )}$ & $(0.99,1.02)$ & $\mathbf{( 1 . 0 2 , 1 . 0 5 )}$ & $\mathbf{( 1 . 0 0 2 , 1 . 0 4 )}$ \\
\hline Age (years) & $\mathbf{0 . 9 7}$ & 1.00 & $\mathbf{0 . 9 7}$ & $\mathbf{0 . 9 8}$ \\
& $\mathbf{( 0 . 9 6 , 0 . 9 8 )}$ & $(0.99,1.01)$ & $\mathbf{( 0 . 9 7 , 0 . 9 8 )}$ & $\mathbf{( 0 . 9 7 , 0 . 9 9 )}$ \\
\hline Weekly exercise & $\mathbf{0 . 9 7}$ & $\mathbf{0 . 9 8}$ & 0.99 & $\mathbf{0 . 9 9}$ \\
volume (minutes) & $\mathbf{( 0 . 9 6 , 0 . 9 8 )}$ & $\mathbf{( 0 . 9 7 , 0 . 9 8 )}$ & $(0.98,1.002)$ & $\mathbf{( 0 . 9 8 , 0 . 9 9 5 )}$ \\
\hline
\end{tabular}

Figure 4 shows the association between the Menstrual Symptom index on the probability of missing/changing training, missing a sporting event/competition, missing work/lectures and pain medication use. Women are more likely to miss training or use pain medication when compared to missing a competition or work. 


\section{Discussion}

In our study, the most common MCS reported included mood changes/increased anxiety, cravings/increased appetite, breast pain/tenderness and increased tiredness/fatigue. Across the total population, $81.1 \%$ of exercising women reported at least one symptom 'often', on average reported having experienced 11.3 (4.4) MCS, out of a maximum of 18, and had a Menstrual Symptom index (factoring in prevalence and occurrence) of 22.9 (11.0) out of a maximum of 54. Experiencing a greater number of MCS more frequently, and therefore having a higher Menstrual Symptom index was associated with a greater likelihood of negative outcomes, including: changing/missing exercise training, missing a sporting event/competition, missing work/lectures and needing to use pain medication as a form of treatment.

Previous research in the general female population has found that up to $90 \%$ of women experience symptoms around menses,[14] and that an increased number of symptoms is associated with a loss of productivity,[15] but this is the first study to investigate MCS in the exercising demographic, and to ascertain potential repercussions associated with these. A major strength of the present study is the large cohort spread across seven geographical territories.

When compared to non-athletes, athletes are more likely to have an irregular menstrual cycle, while also seemingly more likely to suffer certain types of menstrual dysfunction.[16,17] There has been a historical focus on menstrual dysfunctions pertaining to low energy availability in athletes, including amenorrhea and oligomenorrhea,[18] however, little research has evaluated MCS and the impact that these may have on exercise participation and performance among the broader exercising population.

Our data highlight that MCS are common in regularly exercising women, and that MCS are a cause for women to miss or change exercise training and competition, to be absent from work/lectures and to use pain medication for treatment. In the general population, research conducted in a Japanese cohort $(n=19,254)$ found an association between the presence and severity of MCS and both a reduction in productivity and with absenteeism from work. $[15,19,20]$ In the present study, $81.1 \%$ of women reported experiencing at least one symptom 'often', which is comparable to previous data in the general population showing up to $90 \%$ experience MCS.[21] Indeed, some studies have shown that exercise helps with management of MCS, therefore it could be hypothesised that those who exercise are at reduced risk of MCS. A pilot study demonstrated that vigorous exercise reduced pain associated with menstruation,[22] and practising yoga and aerobic exercise have also been found to reduce menstrual pain and menstrual distress.[5,23,24] The mechanism for the potential 'treatment' effect of exercise in eumenorrheic women has yet to be elucidated and may be multifactorial, but is likely dependent on the aetiology of the specific MCS. Two possible hypotheses for a 'treatment' effect include the exercise-induced release of endorphins, [25] and the known anti-inflammatory effects of regular moderate exercise.[26]

In light of the high number of exercising women who experience MCS, and the impact that MCS can have on everyday life, it is important to gain a better understanding of the aetiology of MCS and potential risk factors for MCS. This will aid in a more targeted approach to management and treatment strategies. There are a number of different mechanisms for the manifestation of symptoms. Those hypothesised include changes to neurobiology, resulting in alteration to the serotonergic and gamma-aminobutyric acid systems (GABA);[27] the impact of changes in the release of inflammatory markers[28,29] and reactive oxygen species;[30] in addition to hormone fluctuations, sensitivities to hormonal changes,[36] and an overproduction of prostaglandins.[12,31] Previous studies have identified several risk factors that are associated with the prevalence of both PD and PMS.[11] These include diet, BMI, lifestyle and particular psychological factors.[11,32] While lifestyle, diet and psychological components were beyond the scope of the present study, those with a lower BMI did have fewer and less frequent symptoms. However, it is 
important to note that the symptoms may have been historical, but we do not have corresponding historical BMI data, so this finding must be interpreted with caution. Future research should focus on interventionbased randomised controlled trials to accurately evaluate potential non-pharmacological and medical interventions amongst exercising women to enable more strategic dietary, lifestyle, psychological and medical interventions.

Disruptions to mood states that are related to the menstrual cycle have been shown widely and were the most common symptoms reported by the exercising women in this study. Recent work has shown increased mood disturbances in the mid-luteal phase when compared to the mid-follicular phase, postulating a number of potential mechanisms, including the impact of progesterone-mediated changes to dopaminergic signalling.[33] Interestingly, exercise abolished this disturbance.[33] Given most exercising women report mood changes/anxiety, research focus should be placed on management of these symptoms.

\section{The menstrual symptom index (MSi)}

We quantified the prevalence and frequency of MCS using the Menstrual Symptom index, this tool does not capture the severity of MCS. The association between the MSi and negative outcomes provides some content validity - we report an important first step ahead of formal tool development and evaluation.

Note that that women were more likely to miss/change training or use pain medication than they were to miss work or miss a sporting event/competition. Even with the Menstrual Symptom index above the $95^{\text {th }}$ percentile, the probability of missing a sporting event or competition was less than $0.5(50 \%)$, yet for the same Menstrual Symptom index the probability of missing/changing training or using pain medication is almost $0.9(90 \%)$. This suggests that women are likely to continue to compete even with significant MCS. A recent study examining experiences in elite athletes concluded that fewer negative experiences occur during competition than during training,[6] suggesting that women can override or ignore MCS in certain scenarios. Previous research has also highlighted the reluctance of women to seek medical support to help manage MCS; given the significant impact these are clearly having on everyday life, more resources and open discussion are clearly needed.[4]

Harking back to our comment that while this tool measures menstrual cycle symptom frequency, it does not measure menstrual cycle symptom severity; future studies should interrogate our tool and consider an extended tool that captures symptom severity as well as frequency. Galileo said "measure what is measurable and make measurable what is not so". We appreciate the limitations of the Menstrual Symptom index version 1.0 and we encourage investigators to develop future iterations.

\section{Clinical implications}

Medical professionals and athletic support staff need to be aware of the prevalence and impact that MCS can have in exercising women. In light of the evident potential for associated negative outcomes, screening for MCS is warranted. In an applied setting, given the potential MCS aetiologies, where a large number of MCS are reported by exercising women, extra consideration is warranted when planning training, a need for recovery and overall readiness. Establishing ways to mitigate MCS is also necessary, although efficacy may be individual-specific. The derivation of a Menstrual Symptom index to quantify the frequency and number of symptoms is novel and could pave the way for the future development of a MCS screening tool. This could also be used as a means to monitor the efficacy of non-pharmacological and medical treatment options, as frequent pain medication use can have negative long-term effects.[34,35] In the present study, the most common symptoms experienced by exercising women were mood changes/increased anxiety, cravings/increased appetite, breast pain/tenderness and increased tiredness/fatigue, so interventions and an understanding of the mechanism behind these should be prioritised.

Strengths and Limitations 
We believe this to be the largest study to date of exercising women, including women across seven different geographical territories, and this is a clear strength to this research. Considering the individual nature of each menstrual cycle, and the different potential aetiologies driving symptoms, key timepoints for symptoms are likely to vary. Therefore, in the present study, we purposefully captured symptoms at all times in the menstrual cycle to identify the need for research and medical focus/raised awareness. However, as a result, we were unable to identify the key times in the menstrual cycle where specific symptoms were experienced. When working on an individual athlete basis it is important to capture this information to fully support their individual needs.

In the present study, we excluded those using combined hormonal contraceptives (containing an exogenous oestrogen and a progestin). These act by downregulating endogenous hormones through the inhibition of gonadotrophin-releasing hormone, luteinising hormone and follicle stimulating hormone,[36] having systemic metabolic and inflammatory effects.[37] There are many different formulations of combined hormonal contraception in use worldwide. These can be very helpful in treating menstrual symptoms but can also cause unwanted side effects that may be similar to the symptoms evaluated here. Therefore, we excluded these participants to avoid risk of confounding the results. Due to the negligible systemic metabolic disturbances observed with progestin-only options,[37] these users were included in the analysis.

There are at least 5 limitations of our study.

- All of the data are self-report, so despite all participants being identified as premenopausal, the data are reliant on memory recall.

- The presence of any underlying medical issues was not controlled for in the analysis. Various medical issues may result in worse symptoms, however the aim of the current study was to specifically understand the symptoms experienced by exercising women, so this does not negate the significance here.

- We appreciate that this survey was limited to STRAVA users, who may be more likely to be 1) involved in recreational to elite-level exercise; 2) to be willing to invest in their health and wellness; and 3) and to have access to suitable technology in order to complete the survey. Such factors may add an element of bias and may suggest that the true burden of menstrual cycle symptoms is not captured here. However it could also be argued that those with menstrual symptoms may be more compelled to complete this survey.

- While the women in this study were deemed to be 'exercising women', there was no minimal exercise criteria for inclusion. This was largely due to potential short-term alterations in exercise behaviours that would not capture an accurate picture. The performance level of the participants was not captured; clearly this has the potential to alter whether a sporting event/competition and/or training will be missed.

- We note that a very extensive set of menstrual cycle symptoms were provide for women to choose from; this could affect the validity of the Menstrual Cycle index.

Competing interests: Authors GB, EG, NAL, KM, AS and CRP are employees or consultants with Orreco, creators of the FitrWoman app.

Funding: No sources of funding were used to assist in the preparation of this article. A small grant was received from STRAVA to conduct the survey.

Contributorship: GB, CRP, KM and EG designed the study; GB, AJS and JN contributed to the statistical analysis of data, and GB, CRP, KM, EG, AJS, JN, KEA, NL, RB, JR, KM, and AS all contributed to the interpretation of the results and the writing of the manuscript. 
Data availability statement: Data are available upon reasonable request. The data that support the findings of this study are available on request from the corresponding author, Georgie Bruinvels, via email: georgie.bruinvels@,orreco.com

Patient and/or public involvement: Patients and/or the public were not involved in the design, or conduct, or reporting, or dissemination plans of this research.

\section{References}

1 Daley AJ. Exercise and Primary Dysmenorrhoea. Sports Med 2008;38:659-70. doi:10.2165/00007256200838080-00004

2 Sanctis VD, Soliman AT, Elsedfy H, et al. Dysmenorrhea in adolescents and young adults: a review in different country. Acta Bio-medica Atenei Parmensis 2017;87:233-46.

3 Alonso C, Coe CL. Disruptions of Social Relationships Accentuate the Association Between Emotional Distress and Menstrual Pain in Young Women. Health Psychol 2001;20:411-6. doi:10.1037/02786133.20.6.411

4 Tanaka E, Momoeda M, Osuga Y, et al. Burden of menstrual symptoms in Japanese women - an analysis of medical care-seeking behavior from a survey-based study. Int J Women's Heal 2013;Volume 6:11-23. doi:10.2147/ijwh.s52429

5 Vaghela N, Mishra D, Sheth M, et al. To compare the effects of aerobic exercise and yoga on Premenstrual syndrome. J Educ Heal Promot 2019;8:199. doi:10.4103/jehp.jehp_50_19

6 Findlay RJ, Macrae EHR, Whyte IY, et al. How the menstrual cycle and menstruation affect sporting performance: experiences and perceptions of elite female rugby players. Brit J Sport Med 2020;:bjsports2019-101486. doi:10.1136/bjsports-2019-101486

7 Martin D, Sale C, Cooper SB, et al. Period Prevalence and Perceived Side Effects of Hormonal Contraceptive Use and the Menstrual Cycle in Elite Athletes. Int J Sport Physiol 2018;13:926-32. doi:10.1123/ijspp.2017-0330

8 Bruinvels G, Burden R, Brown N, et al. The Prevalence and Impact of Heavy Menstrual Bleeding (Menorrhagia) in Elite and Non-Elite Athletes. Plos One 2016;11:e0149881. doi:10.1371/journal.pone.0149881

9 Halbreich U, Borenstein J, Pearlstein T, et al. The prevalence, impairment, impact, and burden of premenstrual dysphoric disorder (PMS/PMDD). Psychoneuroendocrino 2003;28:1-23. doi:10.1016/s03064530(03)00098-2

10 Premenstrual syndrome. Int J Gynecol Amp Obstetrics 1995;50:80-4. doi:10.1016/0020-7292(95)900020

11 Management of Premenstrual Syndrome. Bjog Int J Obstetrics Gynaecol 2017;124:e73-105. doi:10.1111/1471-0528.14260

12 Dawood MY. Gynecologic Endocrinology. 1987;:405-21. doi:10.1007/978-1-4613-2157-6_19 
13 Faust L, Bradley D, Landau E, et al. Findings from a mobile application-based cohort are consistent with established knowledge of the menstrual cycle, fertile window, and conception. Fertil Steril 2019;112:450457.e3. doi:10.1016/j.fertnstert.2019.05.008

14 Mauvais-Jarvis F, Clegg DJ, Hevener AL. The Role of Estrogens in Control of Energy Balance and Glucose Homeostasis. Endocr Rev 2013;34:309-38. doi:10.1210/er.2012-1055

15 Schoep ME, Adang EMM, Maas JWM, et al. Productivity loss due to menstruation-related symptoms: a nationwide cross-sectional survey among 32748 women. Bmj Open 2019;9:e026186. doi:10.1136/bmjopen2018-026186

16 Loucks AB, Horvath SM. Athletic amenorrhea: a review. Medicine Sci Sports Exerc 1985;17:56. doi:10.1249/00005768-198502000-00010

17 Loucks AB. Effects of exercise training on the menstrual cycle: existence and mechanisms. Medicine Sci Sports Exerc 1990;22:275. doi:10.1249/00005768-199006000-00001

18 Torstveit MK, Sundgot-Borgen J. Participation in leanness sports but not training volume is associated with menstrual dysfunction: a national survey of 1276 elite athletes and controls. Brit J Sport Med 2005;39:141. doi:10.1136/bjsm.2003.011338

19 Takeda T, Imoto Y, Nagasawa H, et al. Premenstrual Syndrome and Premenstrual Dysphoric Disorder in Japanese Collegiate Athletes. J Pediatr Adol Gynec 2015;28:215-8. doi:10.1016/j.jpag.2014.07.006

20 Frick KD, Clark MA, Steinwachs DM, et al. Financial and Quality-of-Life Burden of Dysfunctional Uterine Bleeding Among Women Agreeing To Obtain Surgical Treatment. Women's Heal Issues 2009;19:70-8. doi:10.1016/j.whi.2008.07.002

21 Angst J, Sellaro R, Stolar M, et al. The epidemiology of perimenstrual psychological symptoms. Acta Psychiat Scand 2001;104:110-6. doi:10.1034/j.1600-0447.2001.00412.x

22 Kannan P, Chapple CM, Miller D, et al. Menstrual pain and quality of life in women with primary dysmenorrhea: Rationale, design, and interventions of a randomized controlled trial of effects of a treadmillbased exercise intervention. Contemp Clin Trials 2015;42:81-9. doi:10.1016/j.cct.2015.03.010

23 Rakhshaee Z. Effect of Three Yoga Poses (Cobra, Cat and Fish Poses) in Women with Primary Dysmenorrhea: A Randomized Clinical Trial. $J$ Pediatr Adol Gynec 2011;24:192-6. doi:10.1016/j.jpag.2011.01.059

24 Yonglitthipagon P, Muansiangsai S, Wongkhumngern W, et al. Effect of yoga on the menstrual pain, physical fitness, and quality of life of young women with primary dysmenorrhea. J Bodyw Mov Ther 2017;21:840-6. doi:10.1016/j.jbmt.2017.01.014

25 Grossman A. Endorphins and exercise. Clin Cardiol 1984;7:255-60. doi:10.1002/clc.4960070502

26 Petersen AMW, Pedersen BK. The anti-inflammatory effect of exercise. J Appl Physiol 2005;98:115462. doi:10.1152/japplphysiol.00164.2004

27 Yonkers KA, Simoni MK. Premenstrual disorders. Am J Obstet Gynecol 2018;218:68-74. doi:10.1016/j.ajog.2017.05.045

28 Puder JJ, Blum CA, Mueller B, et al. Menstrual cycle symptoms are associated with changes in lowgrade inflammation. Eur J Clin Invest 2006;36:58-64. doi:10.1111/j.1365-2362.2006.01591.x 
29 Ma H, Hong M, Duan J, et al. Altered Cytokine Gene Expression in Peripheral Blood Monocytes across the Menstrual Cycle in Primary Dysmenorrhea: A Case-Control Study. Plos One 2013;8:e55200. doi:10.1371/journal.pone.0055200

30 Gaskins AJ, Wilchesky M, Mumford SL, et al. Endogenous Reproductive Hormones and C-reactive Protein Across the Menstrual CycleThe BioCycle Study. Am J Epidemiol 2012;175:423-31. doi:10.1093/aje/kwr343

31 Guo S-W, Mao X, Ma Q, et al. Dysmenorrhea and its severity are associated with increased uterine contractility and overexpression of oxytocin receptor (OTR) in women with symptomatic adenomyosis. Fertil Steril 2013;99:231-40. doi:10.1016/j.fertnstert.2012.08.038

32 Grady-Weliky TA. Premenstrual Dysphoric Disorder. New Engl J Medicine 2003;348:433-8. doi:10.1056/nejmcp012067

33 Freemas JA, Baranauskas MN, Constantini K, et al. Exercise Performance Is Impaired during the MidLuteal Phase of the Menstrual Cycle. Med Sci Sport Exer 2020;Publish Ahead of Print. doi: $10.1249 / \mathrm{mss} .0000000000002464$

34 Marjoribanks J, Ayeleke RO, Farquhar C, et al. Nonsteroidal anti-inflammatory drugs for dysmenorrhoea. Cochrane Db Syst Rev 2015;7:CD001751. doi:10.1002/14651858.cd001751.pub3

35 Warden SJ. Prophylactic misuse and recommended use of non-steroidal anti-inflammatory drugs by athletes. Brit J Sport Med 2009;43:548. doi:10.1136/bjsm.2008.056697

36 Schneider-Thoma J, Efthimiou O, Bighelli I, et al. Second-generation antipsychotic drugs and short-term somatic serious adverse events: a systematic review and meta-analysis. Lancet Psychiatry 2019;6:753-65. doi:10.1016/s2215-0366(19)30223-8

37 Wang Q, Würtz P, Auro K, et al. Effects of hormonal contraception on systemic metabolism: crosssectional and longitudinal evidence. Int J Epidemiol 2016;45:1445-57. doi:10.1093/ije/dyw 147

Figure 1 - Sampling plan and number of participants. Dorado = 'in app' communications (via the STRAVA application); $\mathrm{HC}=$ hormonal contraception.

Figure 2 - Stacked bar chart of the frequency of the different types of symptoms experienced by exercising women $(n=6,812)$ and the frequency of the occurrence within symptom.

Figure 3 - a. Bar chart showing the number of menstrual cycle symptoms reported by each exercising woman $(\mathrm{n}=6,812)$. b. Bar chart of the distribution of Menstrual Symptom index scores based on the self-reported menstrual cycle symptoms and frequency of experiencing these by each exercising woman $(n=6,812)$.

Figure 4 - The fitted probabilities of missing/changing training; missing an event/competition; missing work/lectures; and using pain medication based on Menstrual Symptom index score.

$\mathrm{P}($ outcome $)$ - probability 